\title{
Havayı Kirletme Hakkı Satın Alınabilir mi?: İslam Hukuku'nda Çevrenin Korunması Perspektifinden Kyoto Protokolü ${ }^{1}$
}

\author{
Feyza Cevherli*
}

\section{Zeyneb Hafsa Orhan**}

Received: 30.09 .2021

Accepted: 15.11.2021

DOI: $10.54427 /$ ijisef.1002638

Type: Research Article

\section{Öz}

Çevre, canlı ve cansız varlıkların içinde yaşadığı ve birbirleriyle ilişki içerisinde oldukları alandır. İnsanlar ve ilişki içerisinde oldukları her şey çevre kapsamında kabul edildiğinden çevrenin korunması tüm canlılar için önem arz etmektedir. İslam'da her şey bir denge üzerine kuruludur. Bu nedenle bireyler bu dengeyi tahrip etmemeli, korumak için çaba göstermelilerdir. Bu çalışma, çevre kirliliğinin bir türü olan hava kirliliği meselesini ele almaktadır. Hava kirliliği, canlıların yaşamını olduğu kadar çevreyi de olumsuz etkilemektedir. Günümüzde çevre konusu bağlamında küresel ısınma ve iklim değişikliği gibi problemlerin çözümüne yönelik birçok teşebbüsün olduğu bilinmektedir. Çalışmanın hareket noktasını oluşturan Kyoto Protokolü çevre problemlerinin çözümü için atılan adımlardan biridir. İslam Hukuku'ndaki mülkiyet anlayışı çerçevesinde Kyoto Protokolü'nde bulunan "emisyon ticareti" meselesini ele alan bu çalışma, protokolün sonuçları doğrultusunda çevre konusunda yapılması gerekenlere dair önerilere yer vermektedir. Bu önerilerden en önemlileri bireyler bazında sorumluluk anlayışının geliştirilmesi, kurumlar bazında ise yasal düzenlemeler yapılmasının gerekliliğidir.

Anahtar Kelimeler: İslam Hukuku, Kyoto Protokolü, hava kirliliği, emisyon ticareti, mülkiyet hakkı. Jel Kodlar1: Q50, Q53.

\section{Can the Right to Pollute Air be Purchased?: The Kyoto Protocol from the Perspective of Environmental Protection in Islamic Law}

\begin{abstract}
An environment is an area where living and non-living things live and are in contact with each other. Since people and everything they are in contact with are considered within the context of the environment, the protection of the environment is significant for all living things. Everything in Islam is based on a balance. For this reason, individuals should not destroy this balance. However, they should make an effort to protect it. Our study deals with the issue of air pollution, which is a type of environmental pollution. Air pollution negatively affects the environment as well as the life of living

\footnotetext{
${ }^{1}$ Bu çalışma İkam Working Paper serisindeki "Havayı Kirletme Hakkının Mülkiyeti ve Satın Alımı: İslam Hukuku'nda Çevrenin Korunması Perspektifinden Kyoto Protokolü" başlıklı çalışmanın genişletilmiş halidir.

* YÖK 100/2000 Doktora Bursiyeri, Sakarya Üniversitesi, Sosyal Bilimler Enstitüsü, İslam Ekonomisi ve Finansı Ana Bilim Dalı, feyzacevherli@gmail.com, ORCID: 0000-0002-4423-6539.

** Doç. Dr., İstanbul Sabahattin Zaim Üniversitesi, İslam İktisadı ve Finans, hafsa.orhan@izu.edu.tr, ORCID: 0000-0002-7515-910X
} 
things. Today, it is known that there are many attempts to solve environmental problems such as global warming and climate change. The Kyoto Protocol, which constitutes the starting point of our study, is one of the steps taken to solve environmental problems. This study, which deals with the "emissions trading" issue in the Kyoto Protocol within the framework of the right of ownership in Islamic Law, gives place to suggestions on what should be done about the environment in line with the results of the protocol. Some of these suggestions are that the understanding of responsibility should be developed on the basis of individuals and legal regulations should be made on the basis of institutions.

Keywords: Islamic Law, Kyoto Protocol, air pollution, emissions trading, right of ownership.

Jel Codes: Q50, Q53.

\section{Giriş}

Çevre, canlı ve cansız varlıklardan müteşekkil, bu varlıkların birbirleriyle ilişki içerisinde olduğu ve içinde yaşanılan özel bir alandır. Çevreyi, insanların, diğer canlı ve cansız varlıkların oluşturduğu doğal bir alan olarak da tanımlamak mümkündür. Bu açıdan çevre hayatımızın tamamını kuşatan, insanları, diğer canlıları ve etrafımızdaki tüm varlıkları kapsayan şeylerin bütünüdür.

İslami perspektiften çevre, bireyin yaşamında herhangi bir biçimde etkileşimde olduğu her şeyi içine alan bir olgudur. Birey, içinde bulunduğu coğrafya, birlikte yaşamını sürdürdüğü ve aynı coğrafyayı paylaştığı bütün canlılarla bir ilişki içerisindedir. Bu sebeple yakından uzağa tüm coğrafyalar, insanlar ve canlılar, birey açısından çevre olarak kabul edilebilir (Kocabaş, 2014, s. 132).

Çevre, korunması elzem ve canlılar için oldukça hayati olması sebebiyle üzerinde çokça tartışmanın yapıldığı önemli bir nosyondur. Bugün dünya ülkelerine bakıldığında neredeyse her ülkede çevre krizinin emarelerine rastlamak mümkündür. Kaynakların tükenmesinin, canlı türlerinin yok olma tehlikesiyle karşı karşıya olmasının yanında sınai büyüme ve teknolojik manipülasyon gibi etkenler, içinde bulunulan durumu daha da ağırlaştırmaktadır. Hayatımızı idame ettirmemizi sağlayan temiz hava, su ve toprak gibi unsurlar birçok bakımdan risk altındadır (Tucker ve Grim, 2003, s. 17). Bu sebeple çevre kirliliği, özellikle de havanın kirlenmesi devletlerin de ana gündemlerinden birini oluşturmaktadır. Atmosferi korumaya yönelik olarak atılan bir adım olan ve çeşitli devletlerin katılımcı oldukları Kyoto Protokolü de bu gündemin sonuçlarından biri olarak karşımıza çıkmaktadır. Söz konusu protokol ile devletlere havayı kirletme kotası konulmuş, bununla birlikte bu kotayı aşmaları halinde diğer ülkelerden kota satın alma esnekliği sunulmuştur.

$\mathrm{Bu}$ çalışmanın amacı, İslam Hukuku'nun çevreye verdiği önemi ortaya koymak ve birçok devletin çevre ve hava kirliliğine karşı birleşerek imzalamış oldukları Kyoto Protokolü'nü İslam Hukuku perspektifinden yeni bir bakış açısı ile değerlendirmeye çalışmaktır. Bu amaçla, çalışmada İslam Hukuku'nda çevre meselesi ile ilgili kaynaklar taranmıştır. Aynı zamanda Kyoto Protokolü ile ilgili literatür taramaları yapılmıştır. Elde edilen bilgiler ışığında mesele, 
Havayı Kirletme Hakkı Satın Alınabilir mi?: İslam Hukuku’nda Çevrenin Korunması Perspektifinden Kyoto Protokolü

Kyoto Protokolü'ndeki esneklik mekanizmalarından olan emisyon ticareti özelinde İslam Hukuku'ndaki mülkiyet meselesi bağlamında değerlendirilmiştir.

Bu kapsamda çalışmada, birinci bölümde çevre ve İslam Hukuku'nda çevre tasavvuru ele alınacak, ikinci bölümde İslam Hukuku'nda çevrenin korunması perspektifinden Kyoto Protokolü incelenecek ve son olarak da protokolde sözü edilen havayı kirletme hakkı meselesi İslam Hukuku'ndaki mülkiyet anlayışı bağlamında değerlendirilecektir.

\section{1. Çevre ve İslam Hukuku'nda Çevre Tasavvuru}

Çevre; "Bir şeyin yakını, etrafı, kişinin içinde bulunduğu toplumu oluşturan ortam, hayatın gelişmesinde etkili olan doğal, toplumsal, kültürel dış faktörlerin bütünlü̈̆̈̈" olarak tanımlanmaktadır (Türk Dil Kurumu). Kısaca çevre, canlıların içerisinde yaşamlarını sürdürdükleri tabii ortamdır (Ayverdi, 2011, s. 227).

Çevre kavramı, fiziksel çevre ve toplumsal çevre olarak ikiye ayrılmaktadır. Bireylerin içinde yaşamını sürdürdüğü, varlıklarını ve özelliklerini fiziksel manada algıladıkları ortamlar fiziksel çevredir. Toplumsal çevre ise, fiziksel çevre içerisinde olan bireylerin ekonomik, toplumsal ve siyasal sistemler çerçevesindeki ilişkilerinin bütünü olarak tanımlanmaktadır (Mutlu, 2008, s. 196). İnsan merkezli çevre denildiğinde ise insanın içinde yaşadığı ortam kastedilmektedir (Akdur, 2005, s. 14). Canlı her organizma yaşamını sürdürebilmek için çevresine uyum sağlayabilmelidir. Bu uyum, ilk olarak biyolojik çevrede daha sonra da fiziki çevrede sağlanabilir. İçerisinde yaşanılan doğal çevre üzerinde kurulan sosyal yapılar sosyal hayat alanı olarak tanımlanmakta, sosyal hayat alanı ise doğal çevre üzerinde bireylerin beraber yaşamlarını sürdürmeleri ile somutlaşmaktadır (Baran, 1993, s. 263).

Evrendeki tüm varlıklar birbiriyle ilişkili hiyerarşik bir düzen içerisindedir. Her düzeydeki yapı kendi içerisinde dinamik bir bütündür. Bunun yanı sıra üzerindeki ve altındaki yapılarla bağlantılıdır. Elbette ki insan da varlığı itibari ile bu düzenin bir parçasıdır. Dolayısıyla, bu düzenin koruyuculardan biri, belki de en önemlisi insanlardır. Bu sebeple insan, zihnini bu sistemi koruyabilecek düzeyde şekillendirmelidir. Bunu yaparken de İslam'ın evren ve varlıkla ilgili önerilerinden faydalanmalıdır. İslam, insanları yalnızca inanç ve ibadet konularında sorumlu tutmamakta, yaşamın her yönü ile ilgili tavsiyelerde ve uyarılarda bulunmaktadır (Mert, 2008, s. 26-27). Bunlardan biri de çevre meselesidir.

Tabiat üzerindeki hakimiyet gün geçtikçe artmakta, bu da insan ve tabiat arasındaki dengenin bozulmasına sebep olmaktadır. Nüfus artışları, kentlerdeki kalabalık, doğal kaynakların tüketilmesi, doğal güzelliklerin yok edilmesi, hastalıklardaki artış, insanların tabiat üzerindeki hakimiyetlerini kötü bir şekilde kullanmaları sebebiyledir. İnsanla tabiat arasındaki dengenin bozulduğunun birçok kişi farkındadır. Fakat bu dengesizliğin insan ile Allah arasındaki uyumun bozulması sebebiyle olduğunu herkes fark edememiştir (Nasr, 1982, s.14-18). Zira bu farkındalık için bir yaratıcı olduğu kabulünün yanında derin bir kavrayış gerekmektedir.

İnsanların varlık zincirinin en üst kısmında yer almaları, onları doğanın sahibi yapmaz. Nitekim doğanın tek amacı da sadece insanların ihtiyaçlarını gidermek değildir (Özdemir, 
2003, s. 57). İslam'da her şey bir düzen ve denge içerisinde yaratılmıştır. Kur'ân-1 Kerîm bu dengenin insanlar tarafından bozulmaması gerektiğini bildirmektedir (Kur'ân-1 Kerîm 54: 49). $\mathrm{Bu}$ da çevreyi korumanın vazifelerimizden biri olduğunu açıkça ortaya koymaktadır. Allah'ın yeryüzündeki halifesi olan insan (Kur'ân-1 Kerîm 2: 30), yeryüzünde imar edebilen varlıktır (Kur'ân-1 Kerîm 11: 61). Dolayısıyla kendisine verilen bu yetkiyi, kullanımına verilen kaynakları koruyarak değerlendirmelidir (Haneef, 2002, s. 243; Abu-Sway, 1998).

İslam'da çevre meselesini bu hususlarla sınırlı tutmak doğru olmaz. Zira İslam'a göre insan, çevreye karşı sorumlu olmakla birlikte (Kur'ân-1 Kerîm 45: 13), öncelikle kendisine karşı sorumludur. Burada önemli olan husus; insanın kendisi dahil hiçbir şeyin mutlak sahibi olmamasıdır. Beden, ruh, kalp, akıl ve mal, yani insanın sahip olduğu her şey kendisine emanettir (Kur'ân-1 Kerîm 33: 72) ve bunlar üzerindeki tasarrufları da belli kurallara tâbidir. İnsanın kendisine emanet olan şeylerle olan ilişkisi, onu diğer varlıklardan ayırmaktadır (Çınar, 2014, s. 563). Bu husustaki en belirgin fark, insanın davranışları sebebiyle imtihan edilecek olmasıdır (Kur'ân-ı Kerîm 11: 7). Bu sebeple de insan, doğayı tahrip ederek onun fesadına neden olmamalıdır (Kur'ân-1 Kerîm 30: 41).

İnsanın ruhu, bedeni ve öz malı da çevre kapsamında kabul edilebilmektedir. Dolayısıyla İslam'ın çevreye dair hükümleri tüm bu zikredilenleri de kapsamaktadır. Bu açıdan İslam'daki çevre algısının oldukça geniş ve kapsamlı bir niteliğe sahip olduğu kabul edilebilir (Kocabaş, 2014, s. 132). Bu sebeple İslam Hukuku'nda çevre tasavvurunu ve İslam'ın çevre konusundaki emir ve yasaklarını ele alırken bireyin hayatının tümünü kapsayan ve bütün davranışlarını ilgilendiren bir olgudan bahsedildiği söylenebilir. Çünkü bir Müslüman "çevre”sine karşı sınırsız bir özgürlüğe sahip değildir. İslam Hukuku'na göre onun özgürlüğü, kendisine ve çevresine zarar verdiği veya kendi haklarını ve çevredekilerin hakkını ihlal ettiği yerde bitmektedir. Nitekim İslam Hukuku'nun nihai hedefi, insanların refahını (maslahat) artırmak ve onları kötülükten (mefsedet) uzak tutmaktır (İbn Abdüsselâm, 2000, s.11-12).

İslam düşüncesinde insan ve tabiat Allah'ın bir gaye üzerine yarattı̆̆ı varlıklardır. Bu iki varlığın kendileri için belirlenen rolleri vardır. İnsanla tabiat arasındaki ilişkide, tabiatın insana boyun eğecek şekilde yaratıldığı, buna karşın insanın tabiata karşı iyi veya kötü davranabilme potansiyeliyle yaratıldığı görülmektedir. Zira fizyolojik açıdan insanın, kâinatın ve içindeki her şeyin mimarının katında, konumunu yükselten manevi bir özelliği olduğu bilinmektedir (Çolak, 2008, s. 332). Elbette bu husus İslam düşüncesinde çevrenin daha az değerli olduğu manasında anlaşılmamalıdır. Bilakis Kur'ân-1 Kerîm'in mesajlarının metafizik boyutu hakkıyla anlaşıldığı takdirde insanların çevreye karşı sorumluluk bilinci artacaktır.

\section{2. İslam Hukuku'nda Çevrenin Korunması Perspektifinden Kyoto Protokolü}

Çevre hakkı, bireylerin temel dengeleri muhafaza edilen doğal ortamlarda yaşama hakkıdır. $\mathrm{Bu}$ hakkın konusu, insanların çevre üzerindeki menfaatleridir. Çevre hakkında hak ve ödev kısımlarının birbirinden ayrılması zordur. Zira bu hakta ödev boyutu daha ağırlıklıdır. Hak sahipleri, çevreyi korumalıdır ve korumayanlara karşı önlem almak durumundadır (Keleş, 2013, s. 29). 
Havayı Kirletme Hakkı Satın Alınabilir mi?: İslam Hukuku’nda Çevrenin Korunması Perspektifinden Kyoto Protokolü

İslam Hukuku çevre meselesini, insanlara sunulan nimetler ve insanların bu nimetlere karşı sorumlulukları bakımından ele almakta ve içinde bulunulan bu sistemin mükemmelliğine vurgu yapmaktadır (İpek, 2014, s. 231). Sorumlulukları olan insan, faydasına sunulan nimetlerin sahibi olduğunu zannetmektedir ki bu büyük bir yanılgıdır. İnsan, mesuliyetinin idrakine varabilmeli, çevreye zarar verecek her türlü fiilden uzak durabilmelidir.

Çevre kirliliği sorunu, maalesef insan kaynaklı müdahaleler sonucu ortaya çıkmıştır. İnsanların bitmeyen beklentileri, yenilenemeyen kaynakların tüketimi, yenilenebilen kaynakların tahribatı bu sorunun sebeplerindendir (Baran, 1993, s. 266). Sanayideki ve teknolojideki gelişmelerin yanı sıra insanın çevre üzerindeki hakimiyetinin artması da çevre sorunlarının ortaya çıkış sebeplerindendir. İnsanların diğer canlılardan bir farkı da; içerisinde bulunduğu dengeyi ve şartları değiştirebilecek kabiliyette olmasıdır. İnsan bu kabiliyetini iyi yönde olduğu gibi kötü yönde de kullanabilir (Görmez, 1989, s. 7). Çevre, işte bu kötü yöndeki kullanım sebebiyle yani insanın yeryüzünü sınırsız bir şekilde tüketebileceği bir nesne olarak kullanması sebebiyle zarar görmektedir.

İnsanlık, ekolojik dengenin bozulduğu ve bunun kötü etkilerinin yaşandığı bir çağ içerisindedir. Hava kirliliği, su kirliliği, yeşilliklerin azaltılması, ozon tabakasının delinmesi bu etkiler arasında zikredilebilir (Mert, 2008, s. 25). Bununla birlikte bilgi eksikliği ve vurdumduymazlık da çevre kirliliğinin sebepleri arasındadır. Kur'ân-ı Kerîm açısından meseleyi ele alırsak, bilgi eksikliği de yapılan eylemlerin sonuçlarını öngörememe eksikliği de insanın Allah'tan uzaklaştı̆̆ının belirtileridir (Çişti, 2003, s. 89). Günümüz Batı dünyasına bakıldığında buralarda yaşayan hemen herkes yaşamlarında bir şeylerin eksik olduğunu düşünmektedirler. İnsanları bu düşünceye iten sebeplerden birinin, tabiatın dışarı itilmesi ve yapay bir çevre edinilmesi olduğu söylenebilir (Nasr, 1982, s. 14).

Son yıllarda ekolojik dengenin zarar görmesine engel olmak, çevreyi korumak gibi hususlara sıkça vurgu yapılmaktadır. Bireyler arasında çevre bilinci oluşturmak adına çeşitli faaliyetler gerçekleştirilmektedir. Şüphesiz bu faaliyetlerin bireyler üzerindeki etkisini incelemek, bilimsel çalışmalarda yer bulmalıdır. Burada üzerinde durulması gereken nokta, bireyler üzerindeki çevre bilincinin oluşmasında İslam'ın sağlayacağı katkıdır. Bu manada açıktır ki İslam dini, insanları günlük hayatta yapacakları işlere motive ettiği gibi (Mert, 2008, s. 26), çevre bilinci hususunda da motive eder ve buna katkı sağlar. Çevre ahlakının nazarî ve tatbikî olmak üzere iki yönü vardır ve İslam’ın çevre tasavvuru her iki yönü de kapsamaktadır (Ardoğan, 2012, s. 120).

Günümüzde çevre ve çevre problemleriyle ilgili meselelerin başında küresel 1sınma ve iklim değişikliği gelmektedir. Tarihten günümüze bakılacak olursa, Sanayi Devrimi'ne kadar olan sürede iklim değişikliklerinin doğal sebeplerden olduğu sonucuna varılabilir. Zira bu süreye kadar olan süre içerisinde insan etkilerinin çok fazla olduğu söylenemez. Ancak Sanayi Devrimi ile birlikte hızlı bir gelişme ve endüstrileşme faaliyeti görülmektedir. Bu da iklim değişikliğine sebep olan unsurları harekete geçirmiştir. Bugün insanlar bütün faaliyetleri ile sera gazı emisyonlarındaki artışa neden olmaktadır ki bu artış da iklim değişikliğinin en 
önemli sebeplerinden biridir (Bakış ve Çabuk, 2013, s. 33). Küresel 1sınma, insanların çevrelerine müdahaleleri sebebiyle sera gazının arttı̆̆ının bir belirtisidir. Bunların yanında doğal kaynakların sömürülmesi, hızlı nüfus artışı, ormanların tahrip edilmesi sonucu dünyadaki ekosistem dengesinin bozulması, bireysel bencillik, kısa vadeli ekonomik büyüme gibi etkenler, uzun vadeli çevre bütünlügünü sarsmaktadır (Çişti, 2003, s. 89-90).

Dünya genelinde çevre bilincinin oluşmasıyla birlikte, küresel ısınma ve iklim değişikliği sorununa karşı bölgesel ve küresel ölçekte birçok farklı oluşum meydana gelmiştir. Zira sosyal, ekonomik, güvenlik ve çevre ile ilgili meseleleri ele alan iklim politikaları, sürdürülebilir bir dünya için önemli dayanak noktalarıdır (IPCC, 2001, s. 96). Türkiye'nin 2004 yılında dahil olduğu "Birleşmiş Milletler İklim Değişikliği Çerçeve Sözleşmesi” ve 2009 yılında onayladığı "Kyoto Protokolü" bunlardan biridir (Türkiye Cumhuriyeti Çevre ve Şehircilik Bakanlığı, 2018, s. 74). Birleşmiş Milletler'in 1997'de Japonya'nın Kyoto şehrinde düzenlediği çevre toplantısında katılımcı hükümetler tarafından kabul edilen ve "Birleşmiş Milletler İklim Değişikliği Çerçeve Sözleşmesi" olarak imzalanan bu anlaşmanın hedefi, atmosferdeki sera gazı yoğunluğunun, iklime tehlikeli etki yapmayacak seviyelere indirilmesidir (Yenigün, 2007, s. 10).

Protokolde devletler iki kısma ayrılmaktadır. Ek-1 ülkeleri gelişmiş ülkelerdir, ki belirli emisyon hedefleri konulan ülkeler bunlardır. Ek-2 ülkeleri ise gelişmekte olan ülkelerdir (Finus, 2010, s. 31). Türkiye, gelişmekte olan bir ülke olmasına rağmen Ek-1 ülkeleri arasında yer almaktadır (Türkiye Cumhuriyeti Çevre ve Şehircilik Bakanlığı, 2018, s. 22). Türkiye tarafından hazırlanan stratejilerde enerji, ulaşım, sanayi ve atıkların sera gazı emisyonlarına sebep olan faktörler arasında olduğu belirlenmiştir. Bu emisyonların düşürülmesi, büyük ölçüde temiz ve yenilenebilir enerji kaynağı kullanımı sayesinde enerji üretimi ile gerçekleşebilir (Bakış ve Çabuk, 2013, s. 37). Emisyonları azaltmaya ve iklim değişikliğine ilişkin olan mutabakat, bu protokolün uygulanmasının temel dayanağıdır (UNFCCC, 2018, s. 31). Emisyonların azaltılması, yalnızca iklime değil iklim haricinde de birçok sürdürülebilir kalkınma hedefine katkıda bulunacaktır (Robinson ve Herbert, 2001, s. 145).

\subsection{Kyoto Protokolü'ndeki Esneklik Mekanizmaları}

Kyoto Protokolü'nde Ek-1 taraflarına sera gazı emisyon oranlarını azaltmak için üç esneklik mekanizması sunulmaktadır (Şahin, 2016, s. 7):

2.1.1. Ortak Yürütme Mekanizması: Protokolün 6. maddesinde bulunan bu mekanizmaya göre, emisyon hedefi belirlenen ülke, emisyon hedefi belirlenen diğer bir ülkede emisyon azaltıcı projelere yatırım yaptığı takdirde emisyon azaltma kredisi kazanma hakkına sahip olur ve kazandığı krediler toplam hedeften çıkarılabilir (Karakaya ve Özçağ, 2003, s. 5).

2.1.2. Temiz Kalkınma Mekanizması: Protokolde 12. maddede yer alan bu mekanizmada, emisyon hedefi belirlenen ülke, emisyon hedefinin belirlenmediği az gelişmiş bir ülke ile iş birliği yaparak o ülkede sera gazı emisyonlarını azaltmaya yönelik proje yaptığ takdirde sertifikalandırılmış emisyon indirimi kazanır ve kazanılan indirim hedeften 
Havayı Kirletme Hakkı Satın Alınabilir mi?: İslam Hukuku’nda Çevrenin Korunması Perspektifinden Kyoto Protokolü

düşülebilmektedir (Karakaya ve Özçağ, 2003, s. 5). Ortak Yürütme Mekanizması ile benzer niteliktedir. Ancak Ortak Yürütme Mekanizması gelişmiş ülkelere yönelik iken, Temiz Kalkınma Mekanizması gelişmekte olan ülkelere yönelik mekanizmadır (Özdan, 2014, s.68).

2.1.3. Emisyon Ticareti: Protokolün 17. maddesinde yer alan, aynı zamanda çalışma konumuz olan bu mekanizma, emisyon hedefi belirli olan gelişmiş ülkeler arasında emisyon ticaretini mümkün hale getirmektedir (Algan, 2011, s. 84). Bu madde gereği sera gazı emisyonunu hedeflenenden daha az miktarda kullanan Ek-1 ülkelerinden biri, sera gazı salınım izinlerinin bir kısmını bir başka ülkeye satabilmektedir. Bu uygulama, tarafların salınım işlemlerine yasal bir bağlayıcılık koyma ve tarafların kendi haklarının bir kısmının ticaretini yapmalarına izin vermektedir. Salınımların toplam tutarı, herhangi bir ticaret gerçekleşmeden önceki tutar ile eşit olmalıdır. İşlem sonucunda satılan salınımlar, satan ülkenin kendi tutarından çıkarılıp satın alan ülkenin tutarına eklendiğinden her iki ülkenin yükümlülüklerini yerine getirmeleri hali ile aynı kabul edilir (Türkeş, Sümer ve Çetiner, 2000). Diğer esneklik mekanizmaları proje temellidir, emisyon ticareti ise piyasa temellidir. Bu da bu mekanizmayı diğerlerinden ayırmaktadır (Uzoğlu, 2016, s. 29).

Küresel ısınma sebebiyle meydana gelen iklim değişikliklerini engelleyebilmek için Kyoto Protokolü'nün yükümlülüklerinin etkin bir biçimde yerine getirilmesi gerekmektedir. Birçok gelişmiş ülkenin enerji verimliliği ile ilgili alınan bu önlemleri gerçekleştirmede yetersiz kaldığı görülmektedir. Bunun yanı sıra bu mekanizmaların protokolde bulunan çevresel amaçların tersine kullanılabileceği kaygısı da bulunmaktadır (UNFCCC, 2004, s.19). Aslında emisyon ticareti, ülkelere yerli salınımlarını yükümlülükleri altına düşürebilme hususunda bir teşvik niteliğinde kabul edilebilir. Ancak protokoldeki bu meseleyi ele alan 17. maddede, ticaret ilişkisine dair oranlar, ilkeler, kurallar net bir biçimde ortaya konulmamıştır. Bu belirsizlik, tarafların yükümlülüklerini yerine getirmeleri durumunda dahi salınımlarda bir azalma olmama ihtimalini gözler önüne sermektedir. Bu da küresel 1sınmaya engel olmaya yönelik alınan tedbirler neticesinde, sera gazı salınımlarındaki gerekli azalmanın istenen düzeyde olmadığını göstermektedir (Türkeş ve diğerleri, 2000). Emisyon ticareti sisteminin sağlıklı bir biçimde işleyebilmesi için sunulan önerilerin başında kurum ve kuruluşların sistemlerinin yöntem ve ilkelerini belirlemeleri gerektiği gelmektedir (Aküzüm, 2010, s.114).

Görülmektedir ki, Kyoto Protokolü, küresel 1sınma problemine yüzeysel olarak temas edebilmiştir. Protokolün taraflarının, bölgesel kalkınma hedeflerini de göz önünde bulundurarak, iklim değişikliğinin etkilerine karşın önlem almaları gerekmektedir (Bölgesel Çevre Merkezi, 2006, s. 12). Protokole taraf olan ülkeler, emisyonlarını azaltamamış bilakis yalnızca esneklik mekanizmalarını kullanmış ve bu yüzden protokolün hedefini gerçekleştirememesine sebep olmuşlardır. Bunun yanı sıra gelişmiş ülkeler, bu mekanizmalar aracılığıyla gelişmekte olan ülkelerin haklarını satın alarak bir anlamda bu ülkelerin gelişmelerini de önlemişlerdir (Ayhan, 2010, s. 196). Uzmanlar, bu protokolün eksiksiz olarak uygulanması halinde bile dünyaya en çok on sene zaman kazandırabileceğini 
düşünmektedirler (Şahin, 2016, s. 7). Bunun yanı sıra bu protokolün, kendisinden sonra yapılan çalışmalara bir çerçeve oluşturduğu da yadsınamaz bir gerçektir. İnsan kaynaklı sera gazlarının sebep olduğu iklim değişikliklerinin önlenebilmesi, gelişmiş ülkelerin kaynak kullanımına dikkat etmeleri ve önceliği yerli etkinliklere vermeleri gerekmektedir.

\section{Havayı Kirletme Hakkı Meselesinin İslam Hukuku'ndaki Mülkiyet Bağlamında İncelenmesi}

Çalışmanın bu bölümünde mal ve mülkiyetle ilgili bazı genel bilgilere yer verilecek ve havayı kirletme hakkı mülkiyet perspektifinden ele alınmaya çalışılacaktır. Mülkiyet, mal ile ilgili sahiplik hakkını ifade etmektedir. İslam hukuk literatüründe mal, aynî haklara ve hukukî muamelelere konu olabilen şeydir (Hacak, 2003, s. 461). Yeryüzü ve gökyüzündeki her şeyin mâliki Allah'tır. Allah, mülkünü insanların menfaatine sunmuştur. İnsanın kainat üzerindeki yetkisi, kainat ve içerisindekilerden faydalanabilmesi içindir. Yani malların insanlara izafesi, onlardan faydalanma hakkını ifade etmektedir (Udeh, 1977, s. 56). İnsanların mülkiyetinde olmayıp, onların istifadesine sunulan en önemli şeylerden biri de hiç şüphesiz havadır. Bu bağlamda bölüm içerisinde havanın mal olarak kabul edilip edilmediği ve havayı kirletme hakkının satın alınabilirliği incelenecektir.

Mal kelimesi "Bir şahsın mâlik olduğu nesne" (Fîrûzâbâdî, s. 1059) olarak tanımlanmaktadır. Hanefîler tarafından bu kavram "İnsan tabiatının kendisine meylettiği ve ihtiyaç vakti için biriktirilmesi mümkün olan şey" olarak ifade edilmektedir (İbn Âbidîn, 2000, s. 501). Bu tanıma göre hak ve menfaatler başlı başına mal olarak sayılmaz ve hukukî işlemlere konu olmazlar. Hanefîler'e göre bir şeyin mal olabilmesi için biriktirilebilecek şekilde maddî bir varlığının olması ve ondan faydalanılabilmesi gerekmektedir (Abbâdî, 2000, s. 152). Hanefîler dışındaki Mâlikî, Şâfiî ve Hanbelî İslam hukukçularına göre ise mal, "İnsanlar arasında iktisadî bir değgere sahip ve normal şartlarda ve iradî olarak faydalanılması dinen ve hukuken mümkün olan her şeydir." şeklinde tanımlanmaktadır (Abbâdî, 2000, s. 154-156). Bu tanıma bakıldığında da bir şeyin mal olabilmesi için iktisadî bir değerinin olması ve bu değerin hukukî olarak belirlenmesi gerekmektedir. Bu görüşü belirleyen İslam hukukçuları, mal edinmenin asıl amacının, onun sağladığ1 menfaat olduğunu yani malın değerini menfaatinin belirlediğini söylemektedirler. Onlara göre menfaatler de başlı başına mal sayılır. Bir şeyin mal sayılabilmesi için ihrâzının veya hıyâzetinin mümkün olması gerekmediği görüşündedirler (Yaran, 2011, s. 60). Başka bir ifadeyle insanlar arasında maddî bir değeri olan ve kendinden faydalanılabilen her şey hukukî olarak mal kapsamındadır. Mecelle'de mal; "İnsanın yaratılışına bă̆ı olup gerektiği zaman toplanıp saklanabilen menkul ve gayrimenkul şeylerdir." şeklinde tarif edilmiştir (Mecelle, 126).

Zikredilen tariflere bakıldığında; toprak, eşya, canlı ve bunun gibi mâlik olunan şeylerin mal kapsamında olduğu kabul edilmektedir. Mâliki olunmasa da elde edilmesi ve yararlanılması mümkün olan (denizdeki balık, havadaki kuş vb.) şeyler de mal kabul edilmektedir. Tanımların ışığında hava ve güneş ışığı gibi elde edilmesi mümkün olmayan şeyler ise, faydalı olmalarına rağmen mal olarak kabul edilmemektedirler. Zaman içerisinde teknoloji ile birlikte 
Havayı Kirletme Hakkı Satın Alınabilir mi?: İslam Hukuku’nda Çevrenin Korunması Perspektifinden Kyoto Protokolü

güneş ışınları ya da havanın depolanması mümkün olursa, mal olarak kabul edilebileceği görüşü de mevcuttur (Demir, 1986, s. 19).

Diğer hukuk sistemlerinde olduğu gibi İslam Hukuku'nda da mal, çeşitli açılardan birçok tasnife tâbi tutulmuştur. Bu çalışma kapsamında sahiplerine göre mal çeşitlerini incelenecek olursa, bunlar; mübah mallar, özel mallar, vakıf malları, devletin özel malları ve kamu mallarıdır. Yararlanılması mübah olan ancak mülkiyete konu olmayan mallar, kamu malları olarak kabul edilebilir (Günay, 2001, s. 47). Kamu malları, “Umumun ya da belirli bir yer halkını umum ahalisinin doğrudan doğruya ve serbestçe yararlanmasına terkedilen yerlerdir." (Günay, 2001, s. 145) olarak tanımlanmaktadır. İslam Hukuku kamu mallarından yararlanma hususunda bireylere geniş bir alan tanımıştır. Genellik, eşitlik, serbestlik, zarar vermeme ve ücretsizlik, bu mallardan yararlanmanın şartlarındandır (Günay, 2001, s. 190-200). Devlet, kamu malları üzerinde bir yetkiye sahiptir. Fakat bu yetkilerin hangi haklarda devreye girdiği meselesi önemlidir (Günay, 2001, s. 157).

Anlaşılıyor ki mala mal özelliği kazandıran, insanın onunla olan ilişkisidir. Bu ilişki, insanın onu elde etmesinden kaynaklanmaktadır ki bu da mülkiyet olarak ifade edilmektedir. Mülkiyet sözlükte, "Bir şeyi ele geçirmek ve onun üzerinde tek başına söz sahibi olma gücü" olarak tanımlanmaktadır (Fîrûzâbâdî, s. 954). İslam Hukuku terimi olarak da, "Bir şeyin hukuken engelleyici, olağan dışı bir durum olmadıkça kişiye tek başına o şey üzerinde yetkili olma ve tasarrufta bulunma imkânı sağlayacak şekilde hıyâzet altına alınması" (Ali el-Hafif, 1996, s. 18) olarak açıklanmaktadır. Sahibine eşya üzerinde en kapsamlı yetkileri veren hak (Hacak, 2006, s. 543) olarak tanımlanan mülkiyetin konusu maldır, denebilir. İslam Hukuk Tarihi'ne bakıldığında nelerin mülkiyet konusu olup olmadığı hususunun örfe göre değişiklik gösterdiği görülmektedir. İslam Hukuku'na göre her dönemde değişen ve gelişen özelliklere göre "yararlanma" ve "edinme" konusu olabilecek her şey ictihad yoluyla hukukî işlemlere konu olabilmektedir (Ali el-Hafîf, 1996, s. 18). Mülkiyet hakkı, İslam Hukuku'nun korumak istediği beş esas (makâsıdu'ş-şerîa) arasındadır. Mâlikine kullanma, yararlanma ve harcama gibi haklar veren bu hak, çevre-mülkiyet meselesi bağlamında umumî zararın giderilmesi ve kamu yararı sebepleriyle sınırlandırılabilmektedir (Kurban, 2012, s. 218-219). Mülkiyet, belirli fiziki varlığ olan şeyler üzerinde kurulabildiği gibi, menfaat üzerine de kurulabilmektedir (Çalış, 2013, s. 402).

Tanımlar neticesinde anlaşılmaktadır ki mülkiyet, mal ve aynı hükümde olan menfaatler ile insan arasında bir ilişkidir. Hukuk düzeninin tanıdığı bir haktır ve maldan farklı bir kavramdır. Mal tabiî bir kavram iken, mülkiyet hukukî bir kavramdır. Menfaatlerin mal sayılması tartışmalıdır ama mülk sayılmasında ihtilaf yoktur. Mülkiyet, eşyanın tabiatından gelen bir hak değil, hukuk düzeninin "meşrû sebeplere bağlı" izin ve benimsemesinden doğan bir haktır. Dolayısıyla her hak gibi ancak hukuk düzeninin tanıyp benimsemesiyle varlık kazanir (Karaman, 2001, s. 29-30).

Mülkiyet yetki sahibi açısından; özel mülkiyet, vakıf mülkiyeti, devlet mülkiyeti ve kamu mülkiyeti olarak sınıflandırılmaktadır (Çalış, 2013, s. 406). Kamu mülkiyeti, yollar, akarsular, 
hanlar; yani kamuya ait olan her yeri kapsamına almaktadır. Kamu mülkiyetinden (mübah olan şeylerden), tüm fertlerin başkalarına zarar vermeden eşit derecede faydalanma hakkı vardır (Mecelle, 1254). Bu hususta birçok âyet-i kerîme bulunmaktadır (Kur'ân-1 Kerîm 2: 29; Kur'ân-1 Kerîm 55: 10-12). Hadîs-i şerîflerde de insanların üç şeyde ortak olduğu, bu şeylerin de su, ot ve ateş olduğu bildirilmiştir (Ebû Dâvûd, Büyu', 62). Bu ortaklık, yararlanma açısındandır; mülkiyet ortaklığı şeklinde anlaşılmamalıdır. Bunlardan yararlanmak, güneş ve havadan yararlanmak gibidir ve Müslümanlar ile Müslüman olmayanlar bunlardan eşit olarak yararlanma hakkına sahiptir (Serahsî, 1993, s.164). Zira ortak mallarda bireylerin mülkiyet hakkının olduğunu söylemek doğru olmayacaktır. Resûlullah'ın (sav) biriken suyun satışını yasaklaması (Müslim, Müsâkât, 34; Ebû Dâvûd, İcâre, 61) örneğine bakıldığında da önemli olan hususun satış mülkiyeti olduğu görülmektedir. Çünkü havuzda biriken su, havuz sahibi için mülk edinilmiş bir şey değildir. Bu sebeple satışına izin verilmemiştir (Serahsî, 1993, s.166).

Mülkiyetin konusu nesneler, menfaatler ve haklar olmakla birlikte, mülkiyetin kapsamı yatay ve dikey olarak ele alınabilir. Bir şeye mâlik olmak demek, onun unsurlarına da mâlik olmak anlamina gelmektedir. Örneğin toprak mülkiyetini ele alacak olursak, toprakla birlikte toprağın alt tabakası olduğu gibi toprağın üzerindeki hava boşluğu da mülkiyet altında kabul edilmektedir. Mecelle bu hususa "Kim ki bir yere mâlik olursa altına da üstüne de mâlik olur." maddesiyle işaret etmektedir (Mecelle, 1194). Bazı İslam hukukçuları mülkiyetin dikey açıdan yer altını ve hava boşluğunu kapsamadığı görüşünde olsalar da mülkiyetin amacı doğrultusunda dikey kapsamda yer altında ve hava boşluğunda bir alanı içermesi kaçınılmazdır (Mısrî, 1989, s. 37). Hukuk sistemleri, mülkiyetin dikey açıdan belirli bir bölgeyi ihata ettiğini fakat bu kapsamın da belli sınırları olduğunu kabul etmektedir. Mülkiyetin dikey kapsamının mâlikin faydası ile sınırlandırıldığı kabul edilmekle birlikte; bu sınır da iktisadî faydaya göre belirlenmektedir. Ayrıca teknik gelişmeler de mülkiyetin dikey kapsamını genişleten bir faktördür. Örneğin, önceleri ihrâz özelliği olmadığından güneş enerjisi, hava ile bazı gazlar mal kabul edilmemeleri sebebiyle hukukî işlemlere konu olamamışken; bugün çeşitli gelişmeler sonucu hukukî işlemlere konu olabilmektedirler. Muhakkak ki burada da faydalı olma kriteri ön plandadır (Çalış, 2001, s. 44).

Bir devletin sınırları içerisinde bulunan nehirler, göller vb. şeylerin üzerinde yalnızca o devlet hak sahibidir. Uluslararası denizler, okyanuslar vb. üzerindeki haklar ise hukuksal bakımdan söz konusu edilen şeye yakınlığa bağlı değişmektedir. Uluslararası hukukta kamuya açık kaynaklar tüm insanlığa ait olsa da bunların kullanımında, erken davrananın daha haklı ve daha fazla yarar sağlaması hususu öne çıkmaktadır şeklinde bir görüş bulunmaktadır (Mısrî, 1989, s. 46-47).

Kyoto Protokolü, bu konu açısından önem arz eden ve üzerinde birçok fikir ayrılıklarının bulunduğu 17. maddede, anlaşmaya taraf olan ülkeler için "sera gazı salınımı kotası" belirlemiş ve ülkelerin bu kota hakkını birbirlerine satma esnekliği sunmuştur. Bu bağlamda her ülkenin havayı kirletme hakkı sınırlıdır. Ancak kotasını aşan ülke, kotasını henüz kullanmamış bir ülkenin hakkını ticaret yoluyla satın alabilmektedir. Protokolde emisyon 
Havayı Kirletme Hakkı Satın Alınabilir mi?: İslam Hukuku’nda Çevrenin Korunması Perspektifinden Kyoto Protokolü

ticaretinde bütün sera gazları ile ilgili önlem alınsa da salınımı en çok olan gaz karbondioksit olması sebebiyle, ticareti yapılan gaz karbondioksittir. Bu sebeple bu piyasa, karbon piyasası olarak bilinmektedir (Bayrak, 2012, s. 272). Karbon piyasası ya da karbon ticaretinin ortaya çıkışı, 1997 yılı Kyoto Protokolü ile birlikte gerçekleşmiştir. Protokole katılan ülkeler, doğaya bıraktıkları sera gazlarını belirli bir seviyenin altında tutmak zorundadırlar. Burada amaç, sera gazı salınımını tamamen ortadan kaldırmanın mümkün olmaması sebebiyle, en azından belirli bir seviyede tutmak veya daha fazla salınmasının önüne geçmektir (Peker ve Altınışık, 2011, s. 66).

Karbon piyasasında hava, alınıp satılabilen bir meta olarak kabul edilmektedir. Esasında havanın kendisinin mala dönüştürülmesi pek mümkün olmadığından, hava "havayı kirletme hakkı" olarak piyasada yerini almıştır. Bu şekliyle hava, herkese ait olmaktan çıkıp, onu kirletme hakkının alınabilir ve satılabilir bir mala dönüştüğü mahiyete evrilmiştir. Hava, kimsenin özel mülkiyeti altında değildir. Devletin mülkiyetinin söz konusu olduğu durumlarda bile devlet, kamu yararını öncelemeli, her kaynağı şer̂̂̂ kurallara göre harcamalıdır (Mısrî, 1989, s. 48). Mesele aynî hukuk penceresinden ele alındığında, aynî hak, eşya üzerinde doğrudan doğruya bir hakimiyetin olduğu bir hak olarak tanımlanmaktadır (Karaman, 2001, s. 7). Dolayısıyla mesele aynî haklardan değildir demek yanlış olmayacaktır. Zira ayn mülkiyeti eşyanın kendisine sahip olmak demektir, bu sebeple ayn mülkiyetinden bahsetmek mümkün değildir. Çünkü hava, kimsenin mülkiyeti altında değildir. Menfaat mülkiyeti ise bahsedilen şeyden faydalanma hakkıdır. Allah her şeyi, insanların istifadesine sunduğunu ve mübah kıldığını bildirmektedir. Dolayısıyla, havadan yararlanmanın ticaret metası haline getirilmesi İslam hukuk kaidelerine uygun düşmemektedir.

$\mathrm{Bu}$ noktada Kyoto Protokolü'ne küresel dünyanın ideolojisi olarak da tanımlanan neoliberalizm açısından değinmek yerinde olacaktır. Neoliberalizm, ekonomik ve politik yönetim biçimidir. Bu ideolojiye göre serbest piyasalar kapitalist ekonomiler için en ideal örgütlenme sistemini oluşturmaktadır (Kalkavan ve Baş, 2021, s. 148). Toplumdaki sınıflar arasında mücadele kavramı olarak nitelendirilen neoliberalizm, ideolojik ve politik bir akımı tanımlamaktadır. Neoliberalizm, serbest piyasa kapitalizmi ile bütünleşik yapıda olan, sınıflar arası çatışmayı oluşturan, güç ilişkilerine dayanan bir yönetim sistemi, aynı zamanda ticarette ve sanayide tam serbestliği esas alan bir ideolojidir (Akbaş, 2019, s. 23). Neoliberalizm tartışmalarının merkezinde serbest piyasa sistemi bulunmaktadır. Bu sisteme göre tüketicinin egemenliği, merkezi kontrol veya refah devleti anlayışıyla değil, tam rekabet ilkesine sahip olan serbest piyasa mekanizması ile sağlanır (Sallan Gül, 2004, s. 124-125). Ticaretin ve finansın liberalleştirildiği, piyasaların fiyatları ve enflasyonu belirlemesine izin verildiği ve özelleştirildiği bir sisteme sahip olan neoliberalizm, hem yeni hem klasik liberal düşüncelere dayanmaktadır (Chomsky, 2014, s. 11-12). Neoliberaller kamu malları konusunda devletin piyasaya müdahalesini meşru görmektedir. Kamu malları "bireylerin karşılıklı yararlarının dengelenmesi durumunda ortaya çıkan ihtiyaçların karşılanması" olarak tanımlanmakta fakat nelerin kamu malı olup olmayacağı hususunda uzlaşma sağlanamadığı bilinmektedir (Sallan Gül, 2004, s. 128). Neoliberal politikaların geçerli olduğu küresel düzende yapılmak istenen 
düzenlemeler yapılamamış, alınmak istenen tedbirler alınamamıştır. Çünkü geçmişte olduğu gibi günümüzde de iktisadi kaygılar çevresel kaygılardan daha önce gelmektedir (Kılınç, 2012, s. 158). Neoliberalizm ile birlikte, kamuya ait olan ve hayati öneme sahip olan yerler, özel sektörün piyasa anlayışına göre ayarlanmış ve bu alanlarda kârı maksimize etme amacıyla hareket edilmiştir. Bu alanlara su ve hava gibi kamu mülkiyeti kapsamındaki öğeler de dahil edilmektedir (Kyoto Havayı Kirletme, 2007). Ekolojik varlıklar önceleri özel mülkiyete konu olmazken, doğanın neoliberalleşmesi bu varlıkları piyasa için yatırım aracı haline getirmektedir (Çoban, Özlüer ve Erensu, 2015, s.40). Her şeyin meta haline getirildiği neoliberal sisteme göre, Kyoto Protokolü ile hava da alınıp satılabilen bir meta olarak kabul edilebilmektedir. Oysa her bireyin ve her devletin havadan eşit olarak faydalanma hakkı vardır.

Küresel ısınmaya önlem olarak atılan bir adım olan Kyoto Protokolü'nün, görüldüğü üzere maalesef istenilen sonuçlara ulaşamadığı söylenebilir. Belirlenen hedefin aksine, zikredilen emisyon ticareti sebebiyle devletler havayı daha fazla kirletme hakkına sahip olabilmektedirler. Bu da emisyon ticaretinin finansal bir spekülasyon aracı haline gelmesine sebep olmaktadir.

\section{Sonuç ve Değerlendirme}

Küreselleşen dünya beraberinde birçok problemi getirmektedir. Çevre kirliliği de bu problemlerin başında gelmektedir. Sanayi Devrimi ile birlikte endüstrileşme faaliyetlerinde ve ekonomik alanlarda yaşanan gelişmeler, dünyada insan kaynaklı sera gazı emisyon oranlarındaki artışı da beraberinde getirmiştir. Bu da dünyanın dengesinin bozulmasına, küresel ısınma ve iklim değişikliği problemlerinin ortaya çıkmasına neden olmuş, bir başka ifadeyle yaşanılanların bedelini doğanın ödediği bir sonuç ortaya çıkmıştır. Görülmektedir ki ekolojik krizler, sürdürülebilir kalkınmanın önemini bir kez daha ortaya koymuş ve insanları, çevre üzerindeki olumsuz etkilerini azaltabilmeleri için önlemler almaya yönlendirmiştir. Küresel dünyada etkilerinin fazlasıyla hissedildiği tüm bu durumlar küresel ölçekte adımlar atılmasını gerekli kılmıştır. Kyoto Protokolü de bu adımlardan biridir.

Çevreyi korumak, bireysel olduğu kadar toplumsal bir görevdir. Çevre sorunlarına bir çözüm olarak geliştirilen karbondioksit emisyonunu azaltmanın bir yöntemi olarak ortaya konan emisyon ticareti, sera gazı azaltım hedeflerini dengeleyemeyen ülkelerin azaltım maliyetini düşürmek amacıyla ortaya çıkarılmıştır. Bu emisyon ticaretiyle birlikte atmosferi kirletme haklarının alınıp satılacağı bir piyasa oluşturulmuştur. Bu da atmosferin özelleştirilmeye çalışıldığının bir göstergesidir. Halbuki atmosfer herkesin kullanımına açık olan ve herkesin faydalanabileceği bir şeydir. Üzerinde anlaşılan emisyon ticareti, atmosferi alınıp satılabilen bir meta haline dönüştürmektedir. Bu da herkesin kullanımına açık olan diğer metaların da alınıp satılabileceği liberal piyasalar oluşturulmasına sebep olmaktadır. Bu açlardan Kyoto Protokolü bazı kesimler tarafından neoliberalizmin klasik bir formu olarak kabul edilmektedir. Piyasa dostu bir sistem öngören neoliberalizm, serbest ticaret mekanizmasını esas almaktadır. Bu sistem, problemleri üreten piyasa sisteminin kendi bağlamı içerisinde 
Havayı Kirletme Hakkı Satın Alınabilir mi?: İslam Hukuku’nda Çevrenin Korunması Perspektifinden Kyoto Protokolü

çözümlerinin de piyasa üzerinden üretilmeye çalışıldığı bir sistemdir. Öte yandan emisyon ticareti meselesi, yeni bir mülkiyet hakkı tesis etmektedir. Ancak İslam Hukuku'nda üzerinde umumî ortaklık hakkı bulunan kamu malları, bireylerin de devletin de mülkiyetinde değildir. İslam'da mülkiyet hakkı bağlamında kişinin üzerinde hak iddia edebileceği mallar bulunabilir. Fakat herkesin kullanımına verilen ve ortak kullanımı olan su, ateş ve hava gibi çevre unsurları doğal halleri ile mülkiyet konusu olamamaktadır. Bu mallar üzerinde ancak devletin hüküm ve tasarruf yetkisi bulunmaktadır. Kimsenin mülkiyetinde olmayan bu gibi ortak unsurlar üzerinde herkesin eşit faydalanma hakkı bulunmaktadır. Bu hakta da kullanım ve koruma sorumluğu arasında bağlantı bulunmaktadır. İslam Hukuku'nda bir şeyin sağladığı yarar ona olan sorumluluğun karşılığındadır (Mecelle, 85-87). Bu bağlamda havayı korumak gerekmektedir. Havayı kirletme üzerine hak paylaşımı yapılması İslam hukuk kaidelerine uygun bir fiil olarak değerlendirilemez. Çünkü kimsenin, insanlara tahsis edilmiş olan menfaat mülkiyetini yasaklamaya ve sinırlamaya hakkı yoktur. Bu mülkiyet, insanlara faydalanmaları amacıyla verilmiştir. Herkese ait olan bir şeyin kullanımı üzerinde hak iddia edilemez. Kyoto Protokolü'nde herkesin ortak olduğu bir şeyin kirletme hakkının ticareti söz konusudur. Araştırmalar neticesinde protokolün bu maddesinin, havanın kirlenmesine kota koymak, böylece hava kirliliğinin azaltılmasını sağlamak amacıyla yapıldığı tespit edilmiştir. Ancak bu protokol ile hedeflenen sonuca ulaşılamamıştır. Ticaret sebebiyle de olsa hiçbir ülkenin, başka bir ülkeyi kullanımı ortak olan kaynaklardan mahrum bırakmaya hakkı yoktur.

Kur'ân-1 Kerîm ve diğer kaynaklar incelendiğinde, çevrenin tam mülkiyetinin Allah'a ait olduğu ve insanlara emanet olarak verildiği görülmektedir. Elbette mülkiyet toplumun tasarrufuna verilmiştir, ancak tüm bunları nasıl sarf ettiğimiz oldukça önemlidir. Dolayısıyla insanların tasarrufu altında olan her şeyi nasıl kullandığı, emanetlerine nasıl sahip çıktığı onun sorumluluk anlayışını belirlemektedir. Dünyadaki tüm yaşam biçimlerinin varlığını tehdit eden bir çevre krizinin ortasında, insanın sorumluluk bilinciyle hareket etmesinin büyük bir önemi haizdir.

Küresel düzeyde yapılmaya çalışılan düzenlemelere rağmen, iktisadi meselelerin olduğu yerde çevre ile ilgili meseleler geri planda kalmaktadır. Yapılması gereken, çevre hukuku ile İslam Hukuku arasındaki var zannedilen mesafenin olmadığını kanıtlamaktır. Bu bağlamda İslam çevre hukuku disiplini hakkıyla anlaşılmalı ve bir gerçeklik olarak yol göstermelidir. Anlaşılan odur ki; Müslümanların da bir parçası olduğu küresel düzende İslam Hukuku'nun çevreye dair ilkeleriyle ilgili kurumsal düzenlemeler yapılamadı̆̆ı takdirde çevresel sorunlar tam anlamıyla çözüme kavuşamayacaktır. 
Feyza Cevherli, Zeyneb Hafsa Orhan

\section{Kaynakça}

Abbâdî, A. D. (2000). el-Milkiyye fi'ş-Şeriati'l-İslâmiyye: Tabiatuha ve Vazifetuha. Beyrut: Müessesetü'r-risale.

Abu-Sway, M. (1998). Towards an Islamic Jurisprudence of the Environment. Erişim adresi: http://environment-ecology.com/religion-and-ecology/487-towards-an-islamicjurisprudence-of-the-environment-.html

Ahmed Cevdet Paşa. (1982). Açıklamalı Mecelle: (Mecelle-i Ahkâm-ı Adliyye). A. H. Berki (Haz.). İstanbul: Hikmet Yayınları.

Akbaş, M. E. (2019). Neoliberalizm, Küresel Enerji Sektörü ve Seçilmiş Ülkeler Bazında Elektrik Sektörü Özelleştirmeleri. Social Sciences Research Journal 8(2), 21-43.

Akdur, R. (2005). Avrupa Birliği ve Türkiye'de Çevre Koruma Politikaları “Türkiye'nin Avrupa Birliğine Uyumu". Ankara Üniversitesi Avrupa Topluluğu Araştırma ve Uygulama Merkezi Araştırma Dizisi: 23.

Aküzüm, A. (2010). Enerji Kaynaklı Sera Gazlarını Azaltılması: "Kyoto Protokolü Esneklik Mekanizmaları ve Türkiye" (Yüksek Lisans Tezi). Gazi Üniversitesi.

Algan, M. (2011). Emisyon Ticareti Sistemini Kim Yönetiyor?. Mülkiye Dergisi 35 (273), 81-108. Ali el-Hafîf. (1996). el-Milkiyye fi'ş-şerîati'l-İslâmiyye. Beyrut: Daru'l-Fikr al-Arabi.

Ali el-Hafîf. (2011). İslâm Hukukuna Göre Hukukî Isşlemler ve Hükümleri. (R. Yaran, Çev.). Ahkâmü'l-Muâmelâti'ş-Şer'iyye. Ankara: Türkiye Diyanet Vakfı Yayınları.

Ardoğan, R. (2012). İslam'da Çevre Teolojisinin Pratiğe Yansıması: Çevre Ahlakı. Birey ve Toplum 2/3. 115-143.

Ayhan, D. (2010). Enerji, Çevre ve Sürdürülebilir Kalkınma Bağlamında Küresel İklim Değişikliği Sorunsalı ve Kyoto Protokolü: Türkiye Analizi (Doktora Tezi). Marmara Üniversitesi.

Ayverdi, İ. (2011). Misalli Büyük Türkçe Sözlük. İstanbul: Kubbealtı Neşriyat.

Bakış, R. ve Çabuk, S. N. (2013, Kasım). Uluslararası Türk Dünyası Çevre Sorunları Sempozyumu. Küresel İklim Değişiklikleri ve Su Kaynaklarının Hidroelektrik Enerji Olarak Kullanımı, Eskişehir : 33-38.

Baran, A. G. (1993). Toplum, Birey ve Çevre İlişkileri. Hacettepe Üniversitesi Edebiyat Fakültesi Dergisi 10(1), 261-278.

Bayrak, M. R. (2012). Sürdürülebilir Kalkınma İçin Türkiye'de Düşük Karbon Ekonomisi ve Kyoto Protokolü'nün Finansman Kaynakları. Tarih Kültür ve Sanat Araştırmaları Dergisi $1(4), 266-279$.

Bölgesel Çevre Merkezi. REC Türkiye. (2006). Y. Arıkan (Haz.). Birleşmiş Milletler İklim Değişikliği Çerçeve Sözleşmesi ve Kyoto Protokolü: Metinler ve Temel Bilgiler. Ankara. 
Havayı Kirletme Hakkı Satın Alınabilir mi?: İslam Hukuku’nda Çevrenin Korunması Perspektifinden Kyoto Protokolü

Chomsky, N. (2014). Halk Üzerinden Kazanç Neoliberalizm ve Küresel Düzen. (Çev. S. Evren). İstanbul: Everest Yayınları.

Çalış, H. (2001). İslâm Hukukunda Özel Mülkiyete Getirilen Sınırlandırmalar (Doktora Tezi). Selçuk Üniversitesi.

Çalış, H. (2013). Eşya Hukuku. T. Türcan (Ed.). İslâm Hukuku El Kitabı. (s. 399-420) içinde. Ankara: Grafiker Yayınları.

Çınar, M. (2014). Antep Çevre ve Ahlak Sempoyumu. Çevre-İnsan Arasındaki İlişki "Emanet” Merkezlidir, Antep: 559-567.

Çişti, S. H. H. (2003). Fıtrat: İnsanlar ve Çevre İçin Bir İslâmi Model. R. C. Foltz, F. M. Denny ve A. Baharuddin (Der.). İslam ve Ekoloji: Bahşedilmiş Bir Emanet. (s.89-100) içinde. Nurettin Elhüseyni (Çev.). İstanbul: Oğlak Yayıncılık.

Çoban, A., Özlüer, F. ve Erensu, S. (2015). Türkiye'de Doğanın Neoliberalleştirilmesi ve Bu Sürece Karşı Mücadeleler. A. Çoban (Ed.). Yerel Yönetim, Kent ve Ekoloji. (s. 399-456) içinde. Ankara: İmge Kitabevi Yayınları.

Demir, F. (1986). İslâm Hukukunda Mülkiyet Hakkı ve Servet Dağgllımı. Ankara: Gaye Matbaacılık.

Ebû Dâvûd, es-Sicistânî. Kitâbu's-Sünen. İstanbul: Çağrı Yayınları, 1981.

Finus, M. (2010). B. Engin. (Çev.) Kyoto Protokolü Uygulama Mekanizmaları: Kusurlu mu Yoksa Umut Verici Kavramlar mı?. Sosyal Bilimler Dergisi (2), 30-40.

Fîrûzâbâdî, Muhammed b. Ya'kūb b. Muhammed. (2005). el-Kāmûsü'l-muhîț. (Thk. Muhammad Naim al-Arqousi). Beyrut: Müessesetü'r-risale.

Görmez, K. (1989). Çevre, Çevre Sorunları ve Çevre Politikaları Üzerine Bazı Mülâhazalar. Türkiye Günlüğ̈̈ Dergisi 3, 6-10.

Günay, H. M. (2001). İslâm Hukukunda ve Osmanlı Uygulamasında Kamu Malları. İstanbul: Şule Yayınları.

Hacak, H. (2003). “Mal”. Türkiye Diyanet Vakfı İslâm Ansiklopedisi. Ankara: Türkiye Diyanet Vakf1 Yayınları. 27/461-465.

Hacak, H. (2006). "Mülkiyet". Türkiye Diyanet Vakfı İslâm Ansiklopedisi. İstanbul: Türkiye Diyanet Vakf1 Yayınları. 31/543-548.

Haneef, S. S. S. (2002). Principles of Environmental Law in Islam. Arab Law Quarterly 17(3). 241254.

Intergovernmental Panel on Climate Change (IPCC). (2001). Climate Change 2001: Setting the Stage: Climate Change and Sustainable Development. Contribution of Working Group III to the Third Assessment Report of the IPCC. Cambridge: Cambridge University Press.

İbn Abdüsselâm, İ. (2000). el-Kavâ 'idü'l-kübrâ. Dimaşk: Dâru'l-kalem.

İbn Âbidîn, M. E.. (2000). Reddü'l-muhtâr 'ale'd-Dürri'l-muhtâr. Beyrut: Dâru'l-fikr. 
İslam'da Çevre Hukukunun Prensipleri. (2008). (A. Çolak, Çev.). İslam Hukuku Araştırmaları Dergisi 11, 331-346.

İpek, M. (2014). İslam Kültürü Açısından Çevre-İnsan İlişkisi Üzerine. Dinbilimleri Akademik Araştırma Dergisi 14(3), 227-240.

Kalkavan, H. \& Baş, H. (2021). Neoliberalizm ve İslam Ekonomisinin Sosyal Refah Yaklaşımlarının Karşılaştırılması. ADAM Akademi Sosyal Bilimler Dergisi 11(1), 141-168.

Karakaya, E. ve Özçağ, M. (2003). VII. ODTÜ Ekonomi Konferansı. Türkiye Açısından Kyoto Protokolü'nün Değerlendirilmesi ve Ayriştırma (Decomposition) Yöntemi ile Co2 Emisyonu Belirleyicilerinin Analizi. Ankara.

Karaman, H. (2001). Mukayeseli İslâm Hukuku, I-III, İstanbul: İz Yayıncılık.

Keleş, R. (2013, Kasım) Uluslararası Türk Dünyası Çevre Sorunları Sempozyumu. İnsan Hakkı Olarak Çevre Hakkı. Eskişehir : 29-31.

Khalid, F. Islam and the Environment. M. P. Timmerman(Ed.) Social and Economic Dimensions of Global Environmental Change 5. 332-339.

Kılınç, A. (2012). Neoliberalizm Bağlamında Sürdürülebilir Kalkınmanın Merkez ve Çevre Ülkeler Açısından Değerlendirilmesi. Afyon Kocatepe Üniversitesi İIBBF Dergisi 14(1), 147161.

Kocabaş, S. (2014). Çevre ve Ahlak (Dinin Temel Kaynakları ve Hukuk Bağlamında Çevre-Ahlak İlişkisi) Sempozyum Bildiri Metinleri. Çevreyi Korumaya Esas Teşkil Edecek İslam Hukuku Kaideleri. Gaziantep: 131-151.

Kurban, Y. (2012). İslam Hukuku'nda Çevre-Mülkiyet İlişkisi. EKEV Akademi Dergisi 16(53), 209-222.

Kyoto Havayı Kirletme Hakkına Pazar Sunuyor. (2007). Erişim adresi: https://m.bianet.org/bianet/cevre/92281-kyoto-havayi-kirletme-hakkina-pazar-sunuyor

Mert, M. (2008). İstanbul Üniversitesi İlahiyat Fakültesi Uluslararası Çevre ve Din Sempozyumu, Çevre Bilinci Oluşturmada İslam'ın Katkısı Üzerine. İstanbul.

Misrî, R. Y. (1409/1989). Usûlü'l-iktisâdi'l-İslâmî. Dimaşk: Dâru'l-kalem; Beyrut: ed-Dâru'şŞâmiyye.

Mutlu, Z. (2008). Çevre İçin İnternet / Bilgi ve İletişim Teknolojileri(BIT): e-çevre. Erişim adresi: https://silo.tips/queue/evre-iin-nternet-bilgi-ve-letiim-teknolojileribit-eevre?\&queue $\mathrm{id}=-1 \& v=1608636117 \& u=O D g u M j M w L j E 3 M y 44 O A==$

Müslim, Ebu'l-Hüseyn Müslim b. el-Ḥaccâc. (1981). Sahîhh-i Müslim. thk. Muhammed Fuad Abdülbâkî. İstanbul: Çağrı Yayınları.

Nasr, S. H. (1982). İnsan ve Tabiat. (Çev. N. Avcı). İstanbul: Yeryüzü Yayınları. 
Havayı Kirletme Hakkı Satın Alınabilir mi?: İslam Hukuku’nda Çevrenin Korunması Perspektifinden Kyoto Protokolü

Özdan, S. (2014). Kyoto Protokolü Kapsaminda Emisyon Ticareti, Karbon Borsaları ve Türkiye'ye Yansımaları (Yüksek Lisans Tezi). Marmara Üniversitesi.

Özdemir, İ. (2003) Kur'an Perspektifiyle Bir Çevre Anlayışına Doğru. R. C. Foltz, F. M. Denny ve A. Baharuddin (Der.). İslam ve Ekoloji: Bahşedilmiş Bir Emanet. (s.41-65) içinde. Nurettin Elhüseyni (Çev.). İstanbul: Oğlak Yayıncılık.

Peker, H. S. ve Altınışık, İ. (2011). Negatif Dışsallıkların İçselleştirilmesi Açısından Karbon Ticareti. Gümüşhane Üniversitesi Sosyal Bilimler Elektronik Dergisi 4.

Robinson, J. B. ve Herbert, D. (2001). Integrating Climate Change and Sustainable Development. International Journal of Global Environmental Issues 1 (2). 130-149.

Sallan Gül, S. (2004). Sosyal Devlet Bitti, Yaşasın Piyasa! Yeni Liberalizm ve Muhafazakarlık Kıskacında Refah Devleti. İstanbul: Etik Yayınları.

Serahsî, Ebû Bekir Muhammed b. Ebû Sehl. (1993). el-Mebșût. Beyrut: Dâru'l-Mârife.

Şahin, Ö. U. (2016). Kyoto Protokolü ve Kopenhag Mutabakatının Karşılaştırmalı Analizi. Journal of Awareness 1(1). 5-16.

Şâtibî, İ. M. (1997). el-Muvâfakât fî Usûli'l-Ahkâm. (Şerh: Abdullah Diraz) Dâru'l-Kütübi'lİlmiyye. Beyrut.

Tucker, M. E. ve Grim, J. (2003). R. C. Foltz, F. M. Denny ve A. Baharuddin (Der.). İslam ve Ekoloji: Bahşedilmiş Bir Emanet. (s.17-30) içinde. Nurettin Elhüseyni (Çev.). İstanbul: Oğlak Yayıncılık.

Türk Dil Kurumu güncel sözlük içinde. Erişim adresi: https://sozluk.gov.tr/?kelime=\%C3\%A7evre .

Türkeş, M., Sümer, U. M. ve Çetiner, G. (2000). Küresel İklim Değişikliği ve Olası Etkileri. Çevre Bakanlığı, Birleşmiş Milletler İklim Değişikliği Çerçeve Sözleşmesi Seminer Notları. 7-24, ÇKÖK Gn. Md., Ankara.

Türkeş, M., Sümer, U. M. ve Çetiner, G. (2000). Kyoto Protokolü Esneklik Mekanizmaları. Tesisat Dergisi 52, 84-100.

T.C. Çevre ve Şehircilik Bakanlığı. (2018). Birleşmiş Milletler Kalkınma Programı. Türkiye İklim Değişikliği Yedinci Ulusal Bildirimi. Ankara.

Ûdeh, A. (1977). İslâm'da Mal ve İdâre. (Çev. D. A. Kayapınar). Konya: Sebat Basımevi.

United Nations Framework Convention on Climate Change (UNFCCC). (2004). İklime Özen Göstermek Raporu: İklim Değişikliği Çerçeve Sözleşmesi ve Kyoto Protokolü İçin Kılavuz. Erişim adresi: https://unfccc.int/resource/docs/publications/caring_trk.pdf

United Nations Framework Convention on Climate Change (UNFCCC). (2018). Un Climate Change Annual Report. Erişim adresi: https://unfccc.int/sites/default/files/resource/UNClimate-Change-Annual-Report-2018.pdf 
Feyza Cevherli, Zeyneb Hafsa Orhan

Uzoğlu, Y. (2016). Kyoto Döneminde BM'nin Rolü: Karbon Ticaretinin Çevresel Etkilerinin Iktisadi Analizi (Yüksek Lisans Tezi) Çankırı Karatekin Üniversitesi.

Yenigün, O. (2007). Kyoto Protokolü, Avrupa Birliği ve Türk İş Dünyası. İstanbul. 
Havayı Kirletme Hakkı Satın Alınabilir mi?: İslam Hukuku’nda Çevrenin Korunması Perspektifinden Kyoto Protokolü

\section{Extended Abstract}

The globalizing world brings with it many problems. One of the most important of these is undoubtedly environmental pollution. As time progresses, resources are consumed rapidly, and as a result of the unconscious use of these resources, individuals expose themselves and other living things to unpredictable dangers.

An environment is an area where living and non-living things live and are in contact with each other. Since people and everything they are in contact with are considered within the context of the environment, the protection of the environment is important for all living things. In this respect, the environment is the whole of things that encompasses our entire life, including people, other living things, and all beings around us. From the Islamic perspective, the environment is a phenomenon that encompasses everything with which an individual interacts in any way in his life. The individual is in a relationship with both the geography he lives in and all the living things with which he lives and shares the same geography. For this reason, all geographies, people, and living things, from near to far, can be considered as the environment for the individual. The environment is an important notion on which much debate has been made, as it is essential to protect and vital for living things. In Islam, environmental cleanliness is also closely related to the concept of rights. Because the environment is a space that people share with others. Keeping the environment clean and protecting it is everyone's concern. The main reason for the pollution of the environment and natural resources and the deterioration of the ecological balance is humanity. The problem of environmental pollution has unfortunately emerged as a result of human-induced interventions. The endless expectations of people, the consumption of non-renewable resources, the destruction of renewable resources are the causes of this problem.

Today, when we look at the countries, it is possible to see the signs of an environmental crisis in almost every country. In addition to the depletion of resources and the danger of extinction of living species, factors such as industrial growth and technological manipulation further aggravate the current situation. Elements such as clean air, water, and soil that enable us to sustain our lives are at risk in many respects. For this reason, environmental pollution, especially air pollution, is one of the main agendas of states.

Today, it is known that there are many attempts to solve environmental problems such as global warming and climate change. The Kyoto Protocol, which constitutes the starting point of our study, is one of the steps taken to solve environmental problems. The Kyoto Protocol, which is a step taken to protect the atmosphere and to which various states are participants, also emerges as one of the results of this agenda. With the said protocol, states were given air pollution quotas, and the flexibility to purchase quotas from other countries if they exceeded this quota.

Our study deals with the protection of the environment in Islamic Law, in particular the affordability of the right to pollute the air, which is referred to as emissions trading in the Kyoto Protocol. Protecting the environment is a social task as well as an individual one. The 
goal of the Kyoto Protocol is to reduce the greenhouse gas concentration in the atmosphere to levels that will not have a dangerous effect on the climate. The Kyoto Protocol, a step taken as a precaution against global warming, unfortunately, did not achieve the desired results. Contrary to the determined target, states may have the right to pollute the air more due to the mentioned emissions trading. This causes emissions trading to become a financial speculation tool. On the other hand, the issue of emissions trading establishes a new property right. However, in Islamic Law, public goods that have the right of general partnership are not under the property of individuals or the state. Only the state has jurisdiction over these goods. Everyone has the right to benefit equally from these goods, which are not owned by anyone. It is the duty of society to protect the public goods and public spaces given for the benefit of society. Society should act with a sense of responsibility. It should not be forgotten that our actions do not only concern us but also all humanity. 